\title{
Seeing the Forest Through the Trees: Improving Adherence Alone Will Not Optimize Medication Use
}

\author{
Todd D. Sorensen, PharmD; Deborah L. Pestka, PharmD; Amanda R. Brummel, PharmD, BCACP: \\ Daniel J. Rehrauer, PharmD; and Molly J. Ekstrand, RPh, BCACP, AE-C
}

\begin{abstract}
SUMMARY
Medication adherence is a problem that has received widespread attention in the medical literature and health policy circles. With the increased emphasis on recognizing and rewarding quality in the U.S. health care system, medication adherence measures are increasingly being adopted to assess quality of medication use. However, when adherence is discussed in the literature or evaluated via quality measures, there is rarely any dialogue surrounding adherence in the context of patient-centered issues such as clinical status, individualized medication needs, or personal expectations and social situation.

When nonadherence is identified via a comprehensive assessment of all of a patient's medication-related issues, it typically is recognized as only the third most frequent type of medication-related problem. Issues such as requiring a medication that has not been prescribed or receiving a medication prescribed at a dose too low to achieve the intended clinical goal are more frequently experienced. Furthermore, if a patient is nonadherent to a medication because of adverse effects or if the medication prescribed is not appropriate considering the patient's individual clinical situation, promoting adherence can create unintended harm. Therefore, achieving medication adherence as typically evaluated via existing quality metrics such as proportion of days covered is only valid if the medication is first deemed to be indicated, effective, and safe for the patient.

Medications are the most common medical intervention for chronic illnesses. As a result, success in achieving the Triple Aim of health care is highly dependent on optimizing medication use. When quality measures for medication use narrowly focus on measuring adherence, the resulting programs of payers and providers will likely ignore the most frequent types of medication problems that prevent improved health, create unnecessary costs, and could negatively impact patients' experience with the health care system. Strong leadership and advocacy on the part of agencies in the position to influence the quality measurement landscape in the U.S. health care system will be critical to achieve widespread awareness of medication nonadherence in the context of the full scope of medication-related problems in health care.
\end{abstract}

J Manag Care Spec Pharm. 2016;22(5):598-604

Copyright $\odot 2016$, Academy of Managed Care Pharmacy. All rights reserved.

$\mathrm{N}$ Tonadherence to medications is a universal issue that has garnered significant attention in recent years. Nonadherence has been linked to poor health outcomes, increased hospitalizations, and even death, all of which cost the U.S. health care system billions of dollars..$^{1-4}$ The rapid rise of attention on medication adherence in the health care community is illustrated by a recent PubMed search where 1,782 unique articles were identified with the phrase "medication adherence" in the title. Fifty-one percent of these citations were published between 2012-2015.
While terminology and definitions used to describe adherence vary, adherence to medication is generally defined as the extent to which a patient's behavior corresponds to the treatment recommendation provided by a health care provider. ${ }^{5-7}$ Several methods have been developed to measure adherence, using direct and indirect measures. Each method has its advantages and disadvantages and no gold standard exists. ${ }^{7}$ The most common methods rely on pharmacy claims data and include medication possession ratio (MPR) and proportion of days covered (PDC). PDC is frequently used to determine if adherence standards are met and is the methodology endorsed by the Pharmacy Quality Alliance (PQA). ${ }^{8}$

Although medication adherence has been studied through many lenses, including specific disease states, patient populations, behavioral factors, and economic factors, what is lacking in the literature is a comprehensive analysis of the degree to which nonadherence is a problem in comparison to other types of problems associated with medication use. Furthermore, when analyzing the scope and implications of medication nonadherence, it is typically assumed that the medications to which patients may be nonadherent are the correct medications to be taking, are prescribed at the right dose, and are void of undesirable adverse effects. As a result, poor outcomes or avoidable costs are deemed to be a result of nonadherence alone.

However, when one applies a patient-centered and comprehensive approach to medication problem identification, we posit that the frequency of true medication nonadherence represents only a fraction of the scope of medication-related problems experienced by patients. As a result, maintaining a narrow focus on adherence as a problem will significantly limit the ability to control morbidity and mortality associated with nonoptimal medication use. The objectives of this commentary are to (a) review the focus of medication nonadherence in the literature, (b) outline a broader framework for medicationrelated problems (MRPs), and (c) describe the rates of medication nonadherence identified by health systems employing a comprehensive medication management (CMM) care model.

\section{Focus on Medication Adherence}

\section{in the Literature and Quality Standards}

Medication adherence has been studied extensively, and rates of adherence reported vary widely. Briesacher et al. (2008) compared adherence rates among patients with gout, hypercholesterolemia, hypertension, hypothyroidism, osteoporosis, seizure 
disorders, and type 2 diabetes and found that adherence rates among patients with those disease states ranged from 36.8\%72.3\%. ${ }^{9}$ Yeaw et al. (2009) assessed adherence rates among patients newly initiated on prostaglandin analogs, statins, bisphosphonates, oral antidiabetic medication, angiotensin II receptor blockers, and overactive bladder medication. ${ }^{10}$ After 12 months, adherence rates among participants ranged from $35 \%$ to $72 \% .^{10}$ The World Health Organization states that, on average, adherence among individuals suffering from chronic disease is $50 \% .^{5}$

The potential impact is profound considering that approximately half of all Americans have at least 1 chronic condition. ${ }^{11}$ Nonadherence is said to cost our health care system \$100-290 billion every year, ${ }^{4,7}$ thus, this issue has captured the attention of clinicians, health systems, payers, and policymakers. As a result, adherence has been reported, researched, and scrutinized from multiple perspectives: the health outcomes-related importance of medication adherence, differences in adherence rates across disease states, adherence methodology, return on investment associated with adherence-promoting programs, and the development of quality metrics relating to medication adherence.

In 2010, the National Quality Forum released a consensus report on standards for medication management in which it outlined and endorsed 19 measures for assessing the quality of medication management. ${ }^{12}$ These measures relate to specific medications and chronic illnesses. Of the 19 measures that were developed, 7 directly relate to medication adherence (e.g., MPR for statin therapy in patients with coronary artery disease). ${ }^{12}$ The PQA, a nonprofit alliance with over 100 member organizations, has developed, tested, and endorsed nearly a dozen adherence measures covering a range of drug therapies that are used by drug plans and organizations such as the Centers for Medicare $\&$ Medicaid Services (CMS). ${ }^{13}$ The National Committee for Quality Assurance now includes adherence measures in their Healthcare Effectiveness Data and Information Set (HEDIS) measures. ${ }^{14}$ URAC, an accrediting body for health care organizations, has declared that "medication adherence needs to be a priority for national health policy."15

Since the federal government has developed new programs as part of health care reform, including the coverage of prescription drugs through Medicare Part D, and as quality measures are expanded and enhanced via the Affordable Care Act, medication adherence has received greater attention as a measure of health care quality. CMS utilizes star ratings to evaluate the performance of Medicare Advantage plans and stand-alone prescription drug plans. Beginning in plan year 2012, CMS added adherence measures relating to statins, renin angiotensin system antagonists, and oral diabetes medications measured by PDC. ${ }^{16}$ These measures are triple-weighted because they are viewed as intermediate outcomes. Improving star ratings has become an essential focus for insurers because of the incentives given to high-performing plans, and health plans have placed a priority on raising adherence levels. In plan year 2014, three adherence measures accounted for $11 \%$ of the overall star rating for Medicare Advantage plans and 32\% of the Medicare Part D star rating. ${ }^{17}$ Even small increases in performance measures can raise star ratings. For plan year 2015, Medicare Advantage plans received 3 stars if $73 \%$ of patients with diabetes were adherent to oral medications; 4 stars if $77 \%$ were adherent; and 5 stars if at least $81 \%$ were adherent. ${ }^{18}$

Given the importance of adherence to star ratings, health plans and pharmacy benefit management companies (PBMs) are investing in programs targeting adherence. For example, Optum and RxAnte have created propriety algorithms used to target and reach out to nonadherent patients who are most likely to respond to interventions. PBMs are using adherence as a contracting lever with pharmacies, who are in turn implementing programs to improve adherence in their populations. Other strategies being implemented include enrolling patients in automatic refill programs and synchronizing all of a patient's medications to be filled on the same date.

While the expansion of these adherence-related activities is pursued with good intentions with respect to improving patient health and managing health system costs, these activities largely start with 3 important assumptions: (1) the medication is appropriately indicated for the patient and his or her medical condition; (2) the medication prescribed will achieve the desired clinical effect at the dose prescribed; and (3) the medication will not produce any adverse effects for the patient. Additionally, programs focused on improving adherence also assume that all of the medications needed by a patient have been prescribed-these programs cannot help improve adherence to a medication for which the patient has a need, but for whom it has not been prescribed.

\section{Adherence in the Context of}

\section{Comprehensive Medication Management}

The research and dialogue focused on medication adherence presented in the medical literature and through quality measures rarely describes the application of a systematic, comprehensive approach to the identification of a patient's MRPs - a patient-centered approach ensuring that each medication a patient is taking is indicated, effective, and safe and that the patient is willing and able to take the medication as intended. Evaluations of nonadherence assume that if a patient is prescribed a drug, he or she should be adherent to it. This is reflected in adherence measures that typically rely only on pharmacy claims data. One of the most common methods used to assess adherence is PDC. With this metric, a patient is typically deemed adherent if pharmacy claims indicate that a patient has received sufficient medication to cover $80 \%$ of days within a measurement period. ${ }^{8}$ 
However, adherence should be the goal only when indication, effectiveness, and safety issues have been considered first. ${ }^{19}$ If it is determined that the prescribed medication is not appropriate for the patient or condition, is ineffective (wrong drug for patient or dose is too low), or unsafe (dose is too high or likely to cause an adverse effect), the patient should not be encouraged to be adherent until proper changes to the therapeutic plan are achieved. In fact, if these criteria are not satisfied, patients may experience worse health outcomes in an attempt to make them adherent. The following example illustrates this assertion. It comes from real-world practice, as told by a pharmacist affiliated with an interprofessional inpatient care team.

We had a patient, Terry-with a long history of mental illness and other chronic illnesses, including epilepsy (for which he was prescribed phenytoin) —admitted to our inpatient mental health unit for management of an acute episode of schizophrenia. Upon admission, Terry had no recent history associated with nonmental health illnesses, and his phenytoin level was within the normal range. Over the course of his stay, all medications were administered by the nursing staff as prescribed in the outpatient setting thus ensuring 100\% adherence. After 3 days, the team was making plans to discharge the patient. That day, one of the nurses began to observe Terry exhibiting signs of somnolence and disequilibrium. She asked me to visit and evaluate him. Terry was seated in a chair attempting to put on his shoes as I approached him. Just as I came to his side, he suddenly fell forward. Fortunately, I caught him, preventing an unprotected fall on his face. After checking his phenytoin level, it was found to be significantly above the normal therapeutic range. Unknown to the care team, Terry had been self-managing his epilepsy by decreasing his phenytoin dose, which produced a level that was within normal range. It was only when he was admitted, and he was administered what he had been prescribed that his levels increased to an unsafe level.

While this may be considered an extreme example, it does clearly highlight the unintended consequences of establishing medication adherence without a full understanding of the patient's medication-taking behaviors and evaluation of the indication, effectiveness, and safety of a medication in the context of the individual patient's clinical status. In this case, the patient would have been deemed "nonadherent" with his phenytoin through typical claims-monitoring systems, even though his phenytoin level was normal in the outpatient setting. Achieving adherence ultimately produced an adverse outcome.

\begin{tabular}{|c|c|c|}
\hline \multicolumn{3}{|c|}{$\begin{array}{l}\text { Number of Patients Experiencing At } \\
\text { Least } 1 \text { MRP by Problem Category } \\
\text { in 6,269 Ambulatory Patients }{ }^{a}\end{array}$} \\
\hline $\begin{array}{l}\text { Drug Therapy } \\
\text { Problem Category }\end{array}$ & $\begin{array}{l}\text { Number of } \\
\text { Patients }\end{array}$ & $\begin{array}{c}\text { Percentage of Total } \\
(n=6,269)\end{array}$ \\
\hline Unnecessary drug therapy & 1,999 & 31.9 \\
\hline Needs additional drug therapy & 3,597 & 57.4 \\
\hline Ineffective drug & 1,535 & 24.5 \\
\hline Dose too low & 3,912 & 62.4 \\
\hline Adverse drug reaction & 2,330 & 37.2 \\
\hline Dose too high & 2,333 & 37.2 \\
\hline Nonadherence & 2,554 & 40.7 \\
\hline $\begin{array}{l}\text { Data collected within Fairview } \mathrm{H} \\
\text { bPatients may be reflected in multi } \\
\text { MRP = medication-related problem }\end{array}$ & $\begin{array}{l}\text { em, Janu } \\
\text { ories. }\end{array}$ & \\
\hline
\end{tabular}

A white paper prepared by Medication Management Systems reviewed the occurrence of MRPs of over 20,000 patients receiving CMM services via a model promoted by the PatientCentered Primary Care Collaborative. ${ }^{19}$ In this model, a patient's medications are first evaluated for indication, effectiveness, and safety. Adherence is the final category of evaluation, which includes issues such as affordability, patient understanding, and other factors that may affect adherence. This evaluation demonstrated that of the over 88,000 MRPs that were identified, only $14 \%$ were deemed to be problems where adherence was a core problem in preventing achievement of the intended measure of treatment success. ${ }^{20}$ More compelling is the finding that the most prevalent problem identified among these patients was a need for a medication that had not been prescribed for the patient. The second most common problem was that the dose prescribed was too low for the patient thus not achieving the intended therapeutic effect. Adherence was only the third most frequently identified MRP category.

\section{Health System Data Show Adherence}

\section{Is Not the Most Prevalent MRP}

To further illustrate the type and scope of MRPs experienced by patients, we can look to the experience of 3 health systems that have invested significant effort and resources establishing CMM services as a core element of the health care services they deliver. Fairview Health Services, HealthPartners, and Park Nicollet Health System are large integrated health systems operating in Minnesota, primarily in the Minneapolis-St. Paul metro region. Across these organizations, they have deployed 35.6 full-time equivalents of pharmacists dedicated to providing medication management services in primary and specialty outpatient clinics. The practitioners currently engage in over 20,000 patient encounters annually. ${ }^{21}$ The health systems have established internal management systems that track the number and type of MRPs identified by practitioners through each patient encounter. 
Seeing the Forest Through the Trees: Improving Adherence Alone Will Not Optimize Medication Use

TABLE 2 MRPs Identified Across 3 Health Systems

\begin{tabular}{|c|c|c|c|c|c|c|c|c|}
\hline \multirow[b]{2}{*}{$\begin{array}{l}\text { Health } \\
\text { System }\end{array}$} & \multirow[b]{2}{*}{$\begin{array}{c}\text { Measurement } \\
\text { Period } \\
\end{array}$} & \multicolumn{7}{|c|}{ MRP Categorya } \\
\hline & & $\begin{array}{c}\text { Unnecessary } \\
\text { Drug Therapy } \\
\text { n (\%) }\end{array}$ & $\begin{array}{c}\text { Needs } \\
\text { Additional } \\
\text { Drug Therapy } \\
\text { n (\%) }\end{array}$ & $\begin{array}{c}\text { Ineffective } \\
\text { Drug } \\
\text { n (\%) }\end{array}$ & $\begin{array}{c}\text { Dose Too Low } \\
\text { n (\%) }\end{array}$ & $\begin{array}{l}\text { Adverse Drug } \\
\text { Reaction } \\
\text { n (\%) }\end{array}$ & $\begin{array}{c}\text { Dose Too High } \\
\text { n (\%) }\end{array}$ & $\begin{array}{c}\text { Nonadherence } \\
\mathrm{n}(\%)\end{array}$ \\
\hline Fairview & $\begin{array}{c}\text { January 1, 2009- } \\
\text { December 31, } 2013\end{array}$ & $\begin{array}{c}5,321 \\
(7.4)\end{array}$ & $\begin{array}{l}16,589 \\
(23.0) \\
\end{array}$ & $\begin{array}{c}4,821 \\
(6.7) \\
\end{array}$ & $\begin{array}{r}20,314 \\
(28.2) \\
\end{array}$ & $\begin{array}{l}7,362 \\
(10.2) \\
\end{array}$ & $\begin{array}{c}6,630 \\
(9.2) \\
\end{array}$ & $\begin{array}{l}11,003 \\
(15.3)\end{array}$ \\
\hline HealthPartners & $\begin{array}{c}\text { January 1, 2013- } \\
\text { June 30, } 2014\end{array}$ & $\begin{array}{l}1,667 \\
(8.2) \\
\end{array}$ & $\begin{array}{l}3,038 \\
(15.0)\end{array}$ & $\begin{array}{l}845 \\
(4.2) \\
\end{array}$ & $\begin{array}{l}5,002 \\
(24.7) \\
\end{array}$ & $\begin{array}{l}3,792 \\
(18.7)\end{array}$ & $\begin{array}{l}3,102 \\
(15.3)\end{array}$ & $\begin{array}{l}2,820 \\
(13.9)\end{array}$ \\
\hline Park Nicollet & $\begin{array}{l}\text { August 1, 2012- } \\
\text { July 31, } 2014\end{array}$ & $\begin{array}{c}1,468 \\
(9.1) \\
\end{array}$ & $\begin{array}{l}2,184 \\
(13.6) \\
\end{array}$ & $\begin{array}{l}1,583 \\
(9.8) \\
\end{array}$ & $\begin{array}{l}3,096 \\
(19.2) \\
\end{array}$ & $\begin{array}{l}1,870 \\
(11.6) \\
\end{array}$ & $\begin{array}{l}2,230 \\
(13.8) \\
\end{array}$ & $\begin{array}{l}3,665 \\
(22.8) \\
\end{array}$ \\
\hline Total & & $\begin{array}{c}8,456 \\
(7.8)\end{array}$ & $\begin{array}{c}21,811 \\
(20.1) \\
\end{array}$ & $\begin{array}{l}7,249 \\
(6.7) \\
\end{array}$ & $\begin{array}{r}28,412 \\
(26.2) \\
\end{array}$ & $\begin{array}{l}13,024 \\
(12.0) \\
\end{array}$ & $\begin{array}{c}11,962 \\
(11.0) \\
\end{array}$ & $\begin{array}{c}17,488 \\
(16.1)\end{array}$ \\
\hline
\end{tabular}

ag97 MRPs could not be classified due to free-text entries.

$M R P=$ medication-related problem

To understand the scope of nonadherence when CMM services are used, adherence was examined from 2 different perspectives: (1) what is the rate of nonadherence as an MRP among individual patients where at least 1 problem was identified? and (2) what is the percentage of MRPs associated with nonadherence in relation to all problems identified across the population?

Table 1 describes the frequency of MRPs in individual patients assessed by pharmacists within the Fairview Health System from January 1, 2013, through December 31, 2014, across 7 categories. Data presented in this table were generated by clinical pharmacists responsible for conducting comprehensive medication reviews (CMRs) within primary and specialty care clinics as an integrated member of a patient's health care team. In this cohort, $40 \%$ of individuals were deemed to have an MRP associated with medication nonadherence. This rate is consistent with what is documented in current literature ${ }^{22,23}$; however, it should be noted that these data do not represent the full population of patients taking medications. These data are generated from patients identified as being in need of a CMM evaluation, which typically includes patients who have multiple chronic health conditions, are not achieving clinical goals, and have complex medication regimens. Thus, this rate of nonadherence likely overestimates the true rate across the full population. Although a large number of patients with an adherence-related problem were identified, it is noteworthy that $60 \%$ of patients evaluated were deemed to be experiencing a problem that was not related to medication adherence. The most common MRPs experienced by patients were "dose too low" and "needs additional drug therapy."

The second method of evaluation used was evaluating data from all 3 health systems to determine the frequency of adherence-related problems in relation to all MRPs experienced by patients (Table 2). While each health system used a slightly different method for categorizing MRPs, all schema were based on the 7 MRP categories delineated by the CMM service model. ${ }^{19}$ Results showed that when a comprehensive, patient-centered evaluation process is applied, adherence only represented, on average, $16 \%$ of all MRPs identified. The categories of "dose too low" (26\%) and "needs additional drug therapy" (20\%) were both more frequent than nonadherence. This finding supports the results of other reports evaluating the frequency of MRPs. ${ }^{20,24,25}$

\section{Discussion}

While this assessment does not present scientifically rigorous data, we believe it does shed light on the significance of medication adherence when considered in the context of a comprehensive approach to medication use versus the perspective that one can produce when relying on a narrowly defined data source such as pharmacy claims data. This may explain why strategies intended to improve medication adherence have had varied success. ${ }^{26}$ Without this comprehensive approach, what is labeled as nonadherence may in fact be the symptom of another unresolved problem. Patients may not be adherent to a prescribed regimen because they believe it is unnecessary, ineffective, or because it is causing an undesirable side effect. This can result in the labeling of a patient's behavior as inappropriate when, in fact, it may be conscious nonadherence secondary to a different type of MRP. Similarly, adherence programs may not produce a measurable positive outcome because being deemed adherent to a medication may mask the need for a clinical intervention, for example, achieving a PDC threshold of $80 \%$ with an antihypertensive medication does not confirm that the patient's blood pressure is at goal.

As the health care system continues to evolve from payment for episodes of care and emphasizes rewarding achievement of quality benchmarks, it is critical that metrics used to establish benchmarks truly drive the health care system to produce the Triple Aim (as defined by the Institute for Healthcare 
Improvement) of improved health, better care experience, and reduced per capita costs. ${ }^{27}$ The current emphasis on adherence as a marker of appropriate medication use and measured solely through prescription claims data likely will not fully achieve the promise of the Triple Aim. The majority of MRPs are not related to adherence and, if left unresolved, prevent achievement of desired health outcomes and cost savings associated with well-managed chronic illness. We previously referenced work that projected nonadherence costs in the U.S. health care system at \$100-290 billion each year., ${ }^{4,7}$ But what is the accumulated annual cost of chronic conditions not at goal because a needed medication has not been prescribed or is prescribed at an ineffective (too low) dose? Data presented indicate that both of these types of MRPs present more frequently than nonadherence and thus may potentially create costs in the system that exceed those projected for nonadherence.

This discussion highlights the importance of leadership on the part of entities that are in a position to influence the landscape of measurement focused on medication use. It is imperative that entities outside of pharmacy recognize the limited impact that can be achieved with a narrow focus on medication adherence. The move to include CMR completion rates as a process measure in Medicare Part D hints at changes that recognize a broader scope of issues that must be assessed and managed in order to optimize medication use. However, there remains a critical need to define elements that will support quality associated with CMRs, such as establishing a consistent process of conducting assessments, creating standardized MRP definitions, establishing expectations for patient follow-up evaluations to ensure that identified MRPs have been resolved, and defining outcomes measures that align with a CMM service. In this Viewpoints article, we have described how the existing focus on adherence measurement likely misses more than half of the MRPs associated with chronic medication use in the health care system. The path to addressing all MRPs experienced by patients, thus bringing additional value to patients and payers, is through an agenda that redirects the policy narrative about what is producing suboptimal medication use; advocates for well-defined comprehensive patient care services proven to produce positive clinical, humanistic, and economic outcomes; and is committed to developing, testing, and adopting measurement and reporting systems that detect quality across the spectrum of medication use issues.

\section{Conclusions}

Noted author Stephen Covey, conveying insights regarding the difference between management and leadership, tells a parable about a team traversing a jungle. ${ }^{28}$ We have slightly adapted that story here to align with the theme of this article:
An explorer, who is leading an expedition through a thick forest, has a team working vigorously to cut through the underbrush with machetes. The team is quickly moving forward but hasn't come across its intended destination. It continues to chop and push on, still without finding its target. Finally, the group's leader climbs to the top of one of the tallest trees so he can survey the environment and see if he can spot the illusive destination. As he reaches the top of the tree, his team anxiously awaits his report. After studying the land, he yells down to his men, "I understand the problem. We're in the wrong forest!"

Adherence measures have become widely adopted and are embedded in payment programs such as the CMS star ratings program. This policy agenda likely stems from a concentration of research that has sought to understand MRPs from a narrow data source, creating a narrow perspective. If we move to a higher vantage point to look at the full scope of MRPs, we can see that we are producing a policy agenda that misses more than two thirds of the issues that are driving suboptimal medication use. Without this perspective, it is difficult to recognize that adherence is only a grove of trees in a forest of broader MRPs. With the considerable momentum currently behind measuring, supporting, and reporting medication adherence, substantial leadership and advocacy will be required on the part of influential agencies in order to refocus our health system's quality agenda to address all types of MRPs that are limiting the opportunity for medication use to contribute to the Triple Aim.

\section{Authors}

TODD D. SORENSEN, PharmD, Department of Pharmaceutical Care and Health Systems, and DEBORAH L. PESTKA, PharmD, Social and Administrative Pharmacy, College of Pharmacy, University of Minnesota, Minneapolis. AMANDA R. BRUMMEL, PharmD, BCACP, Clinical Ambulatory Pharmacy Services, Fairview Pharmacy Services, Minneapolis, Minnesota; DANIEL J. REHRAUER, PharmD, Medication Therapy Management Program, HealthPartners, Bloomington, Minnesota; and MOLLY J. EKSTRAND, RPh, BCACP, AE-C, Medication Management Program, Park Nicollet Health Services, St. Louis Park, Minnesota.

AUTHOR CORRESPONDENCE: Todd D. Sorensen, PharmD, Professor and Associate Department Head, Department of Pharmaceutical Care and Health Systems, College of Pharmacy, University of Minnesota, 7-178 Weaver-Densford Hall, 308 Harvard St. SE, Minneapolis, MN 55455. Tel.: 612.625.8645; Fax: 612.625.9931; E-mail: Soren042@umn.edu. 


\section{DISCLOSURES}

No outside funding supported this research. Brummel provides consulting services to other health systems; has received grants from Sanofi and speaking fees from AMCP, APhA, and ASHP; and is on the faculty at the University of Minnesota and employed by Fairview Pharmacy Services. Ekstrand provides consulting services for Alliance for Integrated Medication Management and has received speaking fees from International Diabetes Center and MN Alliance of Physician Assistants. The authors report no other conflict of interest, potential or otherwise.

Study concept and design were contributed primarily by Sorensen, Brummel, and Rehrauer, along with the other authors. Rehrauer, Brummel, and Ekstrand collected the data, which were interpreted by Sorensen, Brummel, Rehrauer, and Ekstrand. Pestka and Sorensen wrote and revised the manuscript, with assistance from the other authors.

\section{REFERENCES}

1. Ho PM, Bryson CL, Rumsfeld JS. Medication adherence: its importance in cardiovascular outcomes. Circulation. 2009;119(23):3028-35. Available at: http://dx.doi.org/10.1161/CIRCULATIONAHA.108.768986. Accessed March 28, 2016.

2. Sokol MC, McGuigan KA, Verbrugge RR, Epstein RS. Impact of medication adherence on hospitalization risk and healthcare cost. Med Care. 2005;43(6):521-30

3. Fitzgerald AA, Powers JD, Ho PM, et al. Impact of medication nonadherence on hospitalizations and mortality in heart failure. J Card Fail. 2011;17(8):664-69.

4. New England Healthcare Institute. Thinking outside the pillbox: a system-wide approach to improving patient medication adherence for chronic disease. NEHI Research Brief. August 2009. Available at: http://www.nehi. net/writable/publication_files/file/pa_issue_brief_final.pdf. Accessed March 28, 2016.

5. World Health Organization. Adherence to long-term therapies: evidence for action. 2003. Available at: http://apps.who.int/iris/bitstream/10665/ 42682/1/9241545992.pdf. Accessed March 28, 2016.

6. Chisholm-Burns MA, Spivey CA. The 'cost' of medication nonadherence: consequences we cannot afford to accept. J Am Pharm Assoc (2003). 2012;52(6):23-826. Available at: http://www.japha.org/article/S15443191\%2815\%2930571-9/fulltext. Accessed March 28, 2016

7. Osterberg L, Blaschke T. Adherence to medication. N Engl J Med. 2005;353(5):487-97.

8. Nau D. Proportion of days covered (PDC) as a preferred method of measuring medication adherence. Pharmacy Quality Alliance. Available at: http://www.pqaalliance.org/images/uploads/files/PQA\%20PDC\%20vs\%20 \%20MPR.pdf. Accessed March 28, 2016.

9. Briesacher BA, Andrade SE, Fouayzi H, Chan KA. Comparison of drug adherence rates among patients with seven different medical conditions. Pharmacotherapy. 2008;28(4):437-43.

10. Yeaw J, Benner JS, Walt JG, Sian S, Smith DB. Comparing adherence and persistence across 6 chronic medication classes. J Manag Care Pharm. 2009;15(9):728-40. Available at: http://www.amcp.org/data/jmcp/728-740.pdf.

11. Ward BW, Schiller JS, Goodman RA. Multiple chronic conditions among U.S. adults: a 2012 update. Prev Chronic Dis. 2014;11:E62. Available at: http://www.ncbi.nlm.nih.gov/pmc/articles/PMC3992293/. Accessed March 28, 2016.
12. National Quality Forum. National Voluntary Consensus Standards for Medication Management: A Consensus Report. Washington, DC: National Quality Forum; 2010. Available at: http://www.qualityforum.org/ Publications/2010/05/National_Voluntary_Consensus_Standards_for_ Medication_Management.aspx. Accessed March 28, 2016.

13. Pharmacy Quality Alliance. PQA performance measures. 2015. Available at: http://pqaalliance.org/measures/default.asp. Accessed March 28, 2016

14. National Committee for Quality Assurance. HEDIS 2015, volume 2. Summary table of measures, product lines and changes. 2015. Available at: http://www.ncqa.org/Portals/0/HEDISQM/Hedis2015/List_of_ HEDIS_2015_Measures.pdf. Accessed March 28, 2016.

15. Honigberg R, Gordan M, Wisniewski AC. Supporting patient medication adherence: ensuring coordination, quality and outcomes. White paper. URAC. 2011. Available at: https://www.urac.org/wp-content/uploads/URACMedAdherence_White\%20Paper.pdf. Accessed March 28, 2016.

16. Kuhle J. Update on medication quality measures in Medicare Part D plan star ratings 2016. Pharmacy Quality Alliance. Available at: http://pqaalliance.org/measures/cms.asp. Accessed March 28, 2016.

17. Leslie RS, Tirado B, Patel BV, Rein PJ. Evaluation of an integrated adherence program aimed to increase Medicare Part D star rating measures. J Manag Care Spec Pharm. 2014;20(12):1193-203. Available at: http://www. jmcp.org/doi/abs/10.18553/jmcp.2014.20.12.1193

18. Centers for Medicare \& Medicaid Services. Trends in Part C \& D star rating measure cut points. Updated November 18, 2014. Available at: https://www.cms.gov/Medicare/Prescription-Drug-Coverage/ PrescriptionDrugCovGenIn/Downloads/2015-Trends-in-Part-C-and-D-StarRating-Measure-Cut-Points-.pdf. Accessed March 28, 2016.

19. Patient-Centered Primary Care Collaborative. The patient-centered medical home: integrating comprehensive medication management to optimize patient outcomes. Resource guide. Second edition. June 2012. Available at: https://www.accp.com/docs/positions/misc/CMM\%20Resource\%20Guide. pdf. Accessed March 28, 2016

20. Strand LM, Cipolle RJ, Frakes MJ. Medication adherence: improved results with comprehensive medication management services. Medication Management Systems. 2013. Available at: http://www.medsmanagement. com/pdf/Adherence\%20manuscript.pdf. Accessed March 28, 2016.

21. Sorensen TD, Sorge LA, Millonig MK, Wallace ML, Schommer J, Pestka D. Integrating medication management: lessons learned from six Minnesota health systems. September 2014. Available at: https://www.pharmacy.umn. edu/sites/pharmacy.umn.edu/files/integrating-medication-managementlessons-learned.pdf. Accessed March 28, 2016.

22. Kimmel SE, Chen Z, Price M, et al. The influence of patient adherence on anticoagulation control with warfarin: results from the international normalized ratio adherence and genetics (IN-RANGE) study. Arch Intern Med. 2007;167(3):229-35

23. Jackevicius CA, Mamdani M, Tu JV. Adherence with statin therapy in elderly patients with and without acute coronary syndromes. JAMA. 2002;288(4):462-67.

24. Isetts BJ, Schondelmeyer SW, Artz MB, et al. Clinical and economic outcomes of medication therapy management services: the Minnesota experience. J Am Pharm Assoc (2003). 2008;48(2):203-11. Available at: http://www.japha. org/article/S1544-3191\%2815\%2931230-9/fulltext. Accessed March 28, 2016. 
25. Ramalho de Oliveira D, Brummel AR, Miller DB. Medication therapy management: 10 years of experience in a large integrated health care system J Manage Care Pharm. 2010;16(3):185-95. Available at: http://www.amcp.org/ data/jmcp/185-195.pdf.

26. Nieuwlaat R, Wilczynski N, Navarro T, et al. Interventions for enhancing medication adherence. Cochrane Database Syst Rev. 2014;11:000011. Available at: http://onlinelibrary.wiley.com/doi/10.1002/14651858.CD000011.pub4/ abstract:jsessionid $=$ CD18445A7E60828FCAA85945E27F0C28.f02t02 Accessed March 28, 2016.
27. Berwick DM, Nolan TW, Whittington J. The triple aim: care, health, and cost. Health Aff (Millwood). 2008;27(3):759-69.

28. Covey SR. The 7 Habits of Highly Effective People. New York: Free Press; 2004. 